\title{
$\underline{\mathbf{P}-35}$
}

\section{Optimization of Extraction Method and Qualitative FT-NMR Analysis on Andrographis Paniculata Leaves}

\author{
Azizul Isha ${ }^{1}$, Mohamad Allif Suyut ${ }^{2}$, Nur A’thifah Yusof ${ }^{1}$ and Intan Safinar Ismail ${ }^{1,2, *}$ \\ ${ }^{1}$ Laboratory of Natural Products, Institute of Bioscience, Universiti Putra Malaysia, 43400 UPM Serdang, Selangor \\ Darul Ehsan, Malaysia; ${ }^{2}$ Department of Chemistry, Faculty of Science, Universiti Putra Malaysia, 43400 UPM \\ Serdang, Selangor Darul Ehsan, Malaysia; E-mail: intan@science.upm.edu.my
}

A study was conducted to optimize the extraction conditions of Andrographis paniculata leaves. Four different solvents, methanol $(\mathrm{MeOH})$, dichloromethane $(\mathrm{DCM})$, ethyl acetate $\left(\right.$ EtOAc) and water $\left(\mathrm{H}_{2} \mathrm{O}\right)$ were used in a period of $1,3,5$ or 7 hours at set water-bath temperature of $25,30,40$ or $60^{\circ} \mathrm{C}$. The extraction dried mass yield of about $200 \pm 0.1 \mathrm{mg}$ fresh cut leaves was measured, and 1D-Nuclear Magnetic Resonance (NMR) profiles were employed to correlate the crude extract weight to the percentage of the main compound, andrographolide, present. Methanol was shown to be the best solvent with $13.75 \%$ yield in 3 hours extraction at $40^{\circ} \mathrm{C}$. The NMR peak intensity analysis of the major compound (andrographolide) also in support of these obtained parameters.

Keywords: Andrographis paniculata, methanol, andrographolide, NMR. 